Egyptian

Orthodontic Journal

\title{
PERCEPTION OF DIFFERENT LIP PROMINENCES IN THE ORTHOGNATHIC FACIAL TYPE BY SAUDI LAYPERSONS
}

\author{
Ali H. Hassan BDS, PhD*
}

\section{ABSTRACT}

The aim of the present study was to identify the most attractive lip prominence in the orthognathic facial profile based on the perception of Saudi Arabian laypersons living in the western region of the country. Lateral photographs of 10 Saudi adult subjects with well proportioned faces were presented to a panel of orthodontists and general dentists to choose the most attractive profiles. Lateral facial photographs were taken using a standardized method for all subjects. The photographs were edited and converted into negatives. One female and one male subject were selected as the supernormal sample. Three different profiles were generated for each of the supernormal subjects by manipulating lip prominence and then presented randomly to laypersons to rank the three profiles in order of attractiveness and to fill out a simple questionnaire. These profiles were: protrusive, average, and retrusive. The percentages of the most attractive lip prominence were calculated, ranked and compared using the chi square test. In the male profiles, the most attractive lip prominence was the average (39.2\%), followed by the retrusive (34.5\%) and then the protrusive (26.3\%) with significant differences between the three lip prominences. In the female profiles, the most attractive profile was the average (46.3\%) followed by the protrusive (37.5\%) and then the retrusive (16.2\%) with significant differences between the three profiles. In conclusion, Saudis seem to prefer average lips in the orthognathic faces in both males and females.

\footnotetext{
* Department of Preventive Dental Sciences, Faculty of Dentistry, King Abdulaziz
} University, Jeddah, Saudi Arabia 
Egyptian

Orthodontic Journal

\section{INTRODUCTION}

Concepts of orthodontic treatment have changed nowadays with more emphasis on the patient's opinion and perception of an ideal facial and dental appearance. Several studies were conducted to evaluate profiles using computer animated and discrete profile generation techniques with different chin, lip and nose prominences and to evaluate them as perceived by different populations. ${ }^{24-}$ 31 In a study conducted to evaluate the perception of lip fullness by a White Caucasian sample, the results showed a sex-effect with females preferring fuller lips than males but both males and females preferred lip fullness greater than Rickett's standards. ${ }^{27}$ Another study compared Mexican American and Caucasian judges in the acceptability of lip protrusion in computer animations of two male and two female subjects of Mexican descent. The results showed that Mexican Americans preferred upper or lower lip positions to be less protrusive than did Caucasians. ${ }^{30}$ In Germany, straight average facial profile was the most attractive as perceived by Germans today, followed by the mildest retrognathic profile and the least attractive were both the extreme retrognathic and prognathic facial profiles. In addition a clear distinction was found between the perception of laypersons and dentists. ${ }^{31}$ In a study to evaluate the perception of a Chinese population of seven computer generated profiles, Chinese male and female profiles that were normal or had bimaxillary retrusion were perceived to be the most attractive by dental professionals, dental students, and laypersons, and the least attractive was the profile with prognathic mandible. ${ }^{32}$ Perception was also found to be different between the general public and professionals especially, orthodontists and maxillofacial surgeons. ${ }^{28,29,32}$

Recently in the western region of Saudi Arabia, cephalometric norms were established for adults and children. ${ }^{33,34}$ Unfortunately, not a single study has been conducted regarding facial profile assessment of the population in the region, which is multi-ethnic in origin. Therefore, establishing facial standards based on the perceptions of Saudi Arabian laypersons is an important task for proper orthodontic diagnosis and treatment.

The objectives of the present study were to identify the most attractive normal lip prominences in the orthognathic facial profile as perceived by Saudi Arabians.

\section{Materials and Methods:}

Lateral facial photographs of 10 Saudi adult subjects with well proportioned faces (pleasant profiles with a Class I dental and skeletal pattern, mesofacial type, average lower face height and lips in good balance and 
harmony) were presented to a panel of orthodontists and general dentists to choose the most attractive profiles. Lateral facial photographs were taken using a standardized method for all subjects. The photographs were taken at a fixed distance of 36 inches from each subject using a digital camera (Cool Pix Nikon TM 5000 camera, Japan), secured on a tripod. Each subject was photographed with the head in natural head posture whereby the visual axis was parallel to the floor. The Adobe Photoshop software (Adobe Systems, Inc San Jose, California) was used to trim the selected photographs, edit them and convert them into negatives. In addition, facial features, such as hairstyle, complexion and make-up were eliminated. The photographs were edited and converted into negatives. One female and one male subject were selected as the most attractive profiles out of the 10 subjects and were used as the supernormal sample.

Lip prominence was manipulated to be average, retrusive and protrusive in male (Figure 1) and female supernormal subjects (Figure 2). Lip prominences were defined as follow: Average-the actual lip position of the selected subjects, protrusive- lips are $2 \mathrm{~mm}$ ahead of the average prominence and retrusive-lips are $2 \mathrm{~mm}$ behind the average prominence. The advancement or retraction of the upper lip was performed from subnasale, lower lip from supramentale, and chin from supramentale. The performed changes were artistically modified to maintain soft tissue continuity. The three generated profiles in male and female were presented randomly to Saudi Arabian laypersons (600 judges) at different governmental and public places in Jeddah, Makkah and Madina which represent the main cities of the western region of Saudi Arabia.

The chosen judges were asked to rank the profiles in order of attractiveness and to fill out a simple questionnaire. The percentage of the most attractive lip prominence was calculated and ranked. The sample used in the present study was distribution free and therefore, Chi square was used to compare the different percentages of attractiveness. The protocol of the present study was approved by the Ethical Committee of the Faculty of Dentistry at King Abdulaziz University.

\section{RESULTS}

In the male orthognathic facial type, the most attractive lip prominence was the average $(39.2 \%)$, followed by the retrusive one $(34.5 \%)$. The least attractive was the protrusive lip prominence $(26.3 \%)$. There was a statistically significant difference between the three groups $(\mathrm{p}<0.05)$ (Table 1). In the female orthognathic facial type, the most attractive lip prominence was also the average $(46.3 \%)$ followed by the protrusive one (37.5\%) and the least attractive was the retrusive one $(16.2 \%)$ with a statistically significant difference between the three groups $(\mathrm{p}<0.05)($ Table 1$)$ 


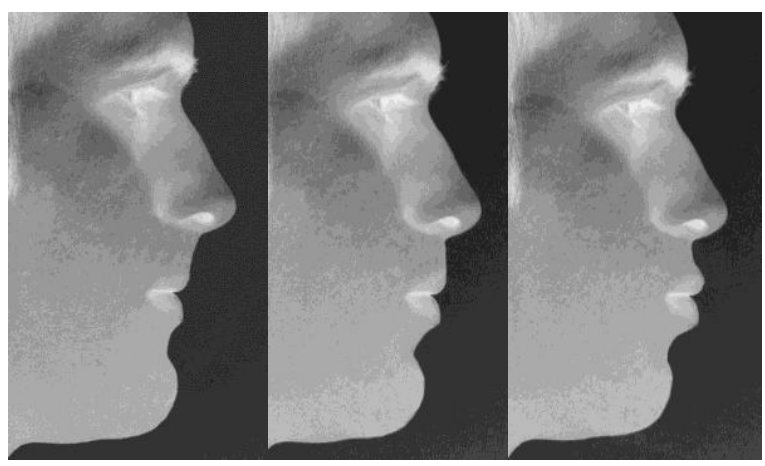

Figure 1: The three generated lip prominences in the orthognathic facial type in the supernormal male subject

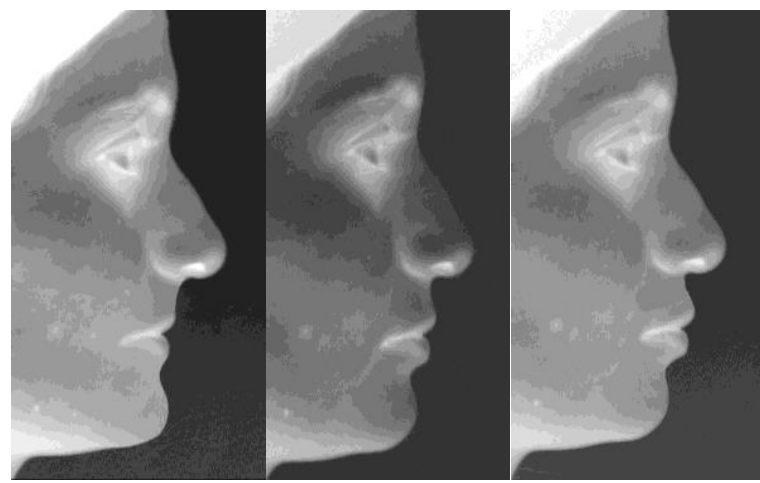

Figure 2: The three generated lip prominences in the orthognathic facial type in the supernormal female subject

Table 1: Different lip prominences in the orthognathic facial type

\begin{tabular}{|cc|c|cc|}
\hline \multicolumn{2}{|c|}{ Male } & \multirow{2}{*}{ Lip Prominence } & \multicolumn{2}{c|}{ Female } \\
\cline { 1 - 1 } n & \% & & $\%$ & n \\
\hline 158 & 26.3 & Protrusive Lip & 37.5 & 225 \\
235 & 39.2 & Average Lip & 46.3 & 278 \\
207 & 34.5 & Retrusive Lip & 16.2 & 97 \\
& $15.19 *$ & $\mathrm{X}^{2}$ & \multicolumn{2}{|c}{$86.59 *$} \\
& 0.001 & $\mathrm{P}$ & \multicolumn{2}{|c}{0.000} \\
\hline
\end{tabular}

* Significant 
Egyptian

Orthodontic Journal

\section{DISCUSSION}

Lip position is critical in orthodontic diagnosis, treatment planning and prognosis. Treating orthodontic patients without taking into account their opinion and chief complaint and depending mainly on their cephalometric features is currently less acceptable. Therefore, the results of the present study are important and should be considered in the treatment of Saudis since they shed some light on the perception of the ideal lip position.

In the present study the perception of an important facial feature that can be influenced by orthodontic treatment (the lip prominence in the orthognathic facial type) was assessed within the normal range values, excluding the extreme features, which don't represent the normal. Unlike previous studies were seven or more images were shown to judges at the same time, ${ }^{25-30}$ only three different profiles were presented in each set to each judge, to help them concentrate more in their selection. In addition, perception of a larger sample was assessed as compared to previous studies. ${ }^{25-30}$

The most attractive lip positions for Saudi were; the average in the male and female orthognathic facial type. Saudis who are known to have bimaxillary protrusion as one of their cephalometric features, ${ }^{21-24,33,34}$ don't prefer protrusive lips. This is in agreement with the perception of Maxican-Americans and opposite to the European Americans. ${ }^{30}$

The present study evaluated the perception of one type of profile, which is the orthognathic facial type. Future studies are necessary to evaluate the perception of the lip prominence in the different facial profiles such as the retrognathic and prognathic and to compare them with the orthognathic facial type, since they represent normal facial types.

\section{CONCLUSION}

The perception of lip prominence is very important to consider during orthodontic treatment. Saudis seem to prefer average but not protrusive lips in orthognathic faces.

\section{REFERENCES}

1. Downs WB. Analysis of the dentofacial profile. Angle Orthod. 1956; 26: 191-212.

2. Downs WB. Variation in facial relationships: their significance in the treatment and prognosis. Am J Orthod. 1948; 34: 812-840. 
3. Riedel RA. The relation of maxillary structures to cranium in malocclusion and in normal occlusion. Angle Orthod. 1952; 22: 142-145.

4. Steiner CC. The use of cephalometrics as an aid to planning and assessing orthodontic treatment. Am J Orthod. 1960;29:8.

5. Bishara SE. Longitudinal cephalometric standards from 5 years of age to adulthood. Am J Orthod. 1981; 79: 35-44.

6. Scheideman GB, Bell WH, Legan HL, Finn RA, Reisch JS. Cephalometric analysis of dentofacial normals. Am J Orthod. 1980; 78: 404-420.

7. Sassouni VA. Roentgenographic cephalometric analysis of cephalofacio dental relationships. Am J Orthod. 1995;41:735.

8. Franchi L, Baccetti T, McNamara JA Jr. Cephalometric floating norms for North American adults. Angle Orthod. 1998; 68: 497-502.

9. Huang WJ, Taylor RW, Dasanayake AP. Determining cephalometric norms for Caucasians and African Americans in Birmingham. Angle Orthod. 1998; 68:503-512.

10. Anderson AA, Anderson AC, Hornbuckle AC, Hornbuckle K. Biological derivation of a range of cephalometric norms for children of African American descent (after Steiner). Am J Orthod Dentofacial Orthop. 2000;118:90-100.

11. Bailey KL, Taylor RW. Mesh diagram cephalometric norms for Americans of African descent. AmJ Orthod Dentofacial Orthop. 1998;114:218-223.

12. Miyajima K, McNamara JA Jr, Kimura T , Murata S, lizuka T . Craniofacial structure of Japanese and European-American adults with normal occlusions and well-balanced faces. Am J Orthod Dentofacial Orthop. 1996;110: 431-438.

13. Engel G, Spolter BM. Cephalometric and visual norms for a Japanese population. Am J Orthod. 1981;80:48-60.

14. Hwang HS, Kim WS, McNamara JA Jr. Ethnic differences in the soft tissue profile of Korean and European-American adults with normal occlusions and well-balanced faces. Angle Orthod. 2002;72:72-80

15. Alcalde RE, Jinno T, Pogrel MA, Matsumura T. Cephalometric Norms in Japanese Adults. J Oral Maxillofac Surg. 1998;56:129-134.

16. Alcalde RE, Jinno T, Orsini MG, Sasaki A, Sugiyama RM, Matsumura T. Soft tissue cephalometric norms in Japanese adults. Am J Orthod Dentofacial Orthop. 2000;118: 84-89. 
17. Loutfy MS, Ponitz P, Harris JE. Cephalometric standards for normal Egyptian face. Egypt Dent J. 1971;17:91-100.

18. Bishara SE, Abdalla EM, Hoppens BJ. Cephalometric comparisons of dentofacial parameters between Egyptian and North American adolescents. Am J Orthod Dentofacial Orthop.1990;97:413-421.

19. Hamdan AM, Rock WP. Cephalometric norms in an Arabic population. $J$ Orthod. 2001;28:297-300.

20. Shalhoub SY, Sarhan OA, Shaikh HS. Adult cephalometric norms for Saudi Arabians with a comparison of values for Saudi and North American Caucasians. Br J Orthod. 1987;14:273-279.

21. Sarhan OA, Nashashibi IA. A comparative study between two randomly selected samples from which to derive standards for craniofacial measurements. J Oral Rehabil. 1988;15:251-255.

22. Al-Jasser NM. Cephalometric evaluation of craniofacial variation in normal Saudi population according to Steiner analysis. Saudi Med J. 2000;21:746-750.

23. Al-Jasser NM. Facial esthetics in a selected Saudi population. Saudi Med J. 2003;24:1000-1005.

24. Arpino VJ, Giddon DB, BeGole EA, Evans CA. Presurgical profile preferences of patients and clinicians. Am J Orthod Dentofacial Orthop. 1998;114: 631-637

25. Giddon DB, Sconzo R, Kinchen JA, Evans CA. Quantitative comparison of computerized discrete and animated profile preferences. Angle Orthod. 1996; $66: 441-8$

26. Kitay D, BeGole EA, Evans CA, Giddon DB. Computer-animated comparison of self-perception with actual profiles of orthodontic and nonorthodontic subjects. Int J Adult Orthodon Orthognath Surg. 1999;14:125-134

27. Cochrane SM, Cunningham SJ, Hunt NP. Perception of facial appearance by orthodontists and the general public. J Clin Orthod. 1997;16:164-168.

28. Cochrane SM, Cunningham SJ, Hunt NP. A comparison of the perception of facial profile by the general public and 3 groups of clinicians. Int J Adult Orthodon Orthognath Surg. 1999;14:291-295

29. Mejia-Maidl M, Evans CA, Viana G, Anderson NK, Giddon DB. Preferences for facial profiles between Mexican Americans and Caucasians. Angle Orthodontist: 2005;75:953-958. 
Egyptian

Orthodontic Journal

30. Honn M, Dietz K, Godt A, Goz G. Perceived relative attractiveness of facial profiles with varying degrees of skeletal anomalies. J Orofac Orthop. 2005; 66:187-196.

31. Soh J, Chew MT, Wong HB. A comparative assessment of the perception of Chinese facial profile esthetics. Am J Orthod Dentofacial Orthop. 2005;127 : 692-699.

32. Hassan AH. Cephaloetric Norms for Saudi Adults living in the Western Region of Saudi Arabia. Angle Orthod 2006;76:18-22, in press.

33. Hassan AH. Cephalometric norms for the Saudi children living in the western region of Saudi Arabia: a research report. Head \& Face Medicine 2005;1:5. 